\title{
MGR-DCB: A Precise Model for Multi-Constellation GNSS Receiver Differential Code Bias
}

\author{
Mohamed Abdelazeem ${ }^{1,2}$, Rahmi N. Çelik ${ }^{1}$ and Ahmed El-Rabbany ${ }^{2}$ \\ ${ }^{1}$ (Geomatics Engineering Department, Istanbul Technical University, Turkey) \\ ${ }^{2}$ (Civil Engineering Department, Ryerson University, Canada) \\ (E-mail: moh.azm84@gmail.com)
}

\begin{abstract}
In this study, we develop a Multi-constellation Global Navigation Satellite System (GNSS) Receiver Differential Code Bias (MGR-DCB) model. The model estimates the receiver DCBs for the Global Positioning System (GPS), BeiDou and Galileo signals from the ionosphere-corrected geometry-free linear combinations of the code observations. In order to account for the ionospheric delay, a Regional Ionospheric Model (RIM) over Europe is developed. GPS observations from 60 International GNSS Servoce (IGS) and EUREF reference stations are processed in the Bernese-5.2 Precise Point Positioning (PPP) module to estimate the Vertical Total Electron Content (VTEC). The RIM has spatial and temporal resolutions of $1^{\circ} \times 1^{\circ}$ and 15 minutes, respectively. The receiver DCBs for three stations from the International GNSS Service Multi-GNSS Experiment (IGS-MGEX) are estimated for three different days. The estimated DCBs are compared with the MGEX published values. The results show agreement with the MGEX values with mean difference and Root Mean Square Error (RMSE) values less than $1 \mathrm{~ns}$. In addition, the combined GPS, BeiDou and Galileo VTEC values are evaluated and compared with the IGS Global Ionospheric Maps (IGS-GIM) counterparts. The results show agreement with the GIM values with mean difference and RMSE values less than 1 Total Electron Content Unit (TECU).
\end{abstract}

\section{KEYWORDS}

\section{Multi-Constellation GNSS. 2. Differential Code Bias.}

Submitted: 10 May 2015. Accepted: 15 November 2015. First published online: 14 December 2015.

1. INTRODUCTION. Global Navigation Satellite Systems (GNSS) have traditionally been used to investigate the spatio-temporal characteristics of the ionosphere Total Electron Content (TEC), both at the regional and the global levels. For precise estimation of the TEC, however, the Differential Code Bias (DCB) (i.e., difference in the code hardware delays at two different frequencies) for both of the satellites and the receiver must be accounted for. The satellite DCB values are stable over one day, while the receiver DCBs are not as stable (Sardon and Zarraoa, 1997; Schaer, 1999).

Earlier studies focused on the estimation of Global Positioning System (GPS) differential code bias (e.g., Arikan et al., 2008; Choi et al., 2011; Jin et al., 2012; Keshin, 
2012; Kao et al., 2013). Keshin (2012) developed a model for receiver DCB estimation using vertical TEC values obtained from the IGS-GIM. The receiver DCBs and vertical residual ionospheric delays were computed using the least-squares estimation approach with linear constraints. The estimated values were compared with those of the IGS counterparts. The results showed agreement with the IGS values with differences less than $1 \mathrm{~ns}$.

More recently, the DCBs for the new BeiDou and Galileo multi-GNSS signals were investigated by a number of researchers (e.g., Li et al., 2012; Montenbruck et al., 2014; Wei et al., 2014; Zhang et al., 2014). Montenbruck et al. (2014) developed the multiGNSS DCB estimation model for both the receivers and satellites. The DCBs for the legacy and modernised GPS, Galileo and BeiDou signals were determined using data collected from the IGS-MGEX network. The IGS-GIM was used in order to remove the ionospheric contribution from the dual frequency pseudorange differences. The estimated DCBs were compared with the group delay parameters transmitted through the GNSS broadcast ephemeris data. The findings showed good agreement with the broadcast parameters.

Ionospheric modelling using multi-GNSS measurements has been investigated by a number of researchers (e.g., Julien et al., 2012; Tu et al., 2013; Tang et al., 2014; Zhang et al., 2015). In Zhang et al. (2015), a regional ionosphere delay model is built over China using data from BeiDou only, GPS only, and combined GPS/BeiDou. The results show that the combined GPS/BeiDou model can significantly improve the accuracy of the estimated TEC and DCBs.

The objective of this research is to develop a multi-frequency multi-GNSS receiver differential code bias model. The receiver DCBs for the legacy and modernised GPS, Galileo and BeiDou signals are estimated based on ionosphere-corrected geometryfree linear combinations of the pseudorange observations. One way to remove the ionospheric delay from the pseudorange differences is to use the IGS-GIM model (Montenbruck et al., 2014). Unfortunately, however, the IGS-GIM model has a limited spatiotemporal resolution. To overcome this problem, a Regional Ionospheric Model (RIM) over Europe is developed in this research. The developed RIM has spatial and temporal resolutions of $1^{\circ} \times 1^{\circ}$ and 15 minutes, respectively. The accuracy of the developed RIM is validated for PPP applications. It is found that the positioning accuracy of the proposed RIM is superior to that of the IGS-GIM, where the RMSE values are reduced from \pm 0.325 to $0.25 \mathrm{~m}$ and from \pm 0.904 to $0.499 \mathrm{~m}$, for the horizontal and height components, respectively (Abdelazeem et al., 2015). In order to produce the RIM, GPS observations from a regional network consisting of 60 International GNSS Service (IGS) and EUREF reference stations are processed in the Bernese-5.20 PPP module in order to estimate the VTEC values. The resulting MGR-DCB model is validated for receiver DCBs estimation for three IGS-MGEX stations on three different days. The estimated DCBs are compared with the publicly available IGS-MGEX values. The findings reveal that the estimated DCBs have good agreement with the MGEX values with mean difference and RMSE values less than 1 ns. In addition, the combined GPS, BeiDou and Galileo VTEC are assessed and compared with the IGS-GIM counterparts. It is shown that the combined VTEC values have mean difference and RMSE values less than 1 TECU with respect to the IGS-GIM counterparts. 
2. PROPOSED MGR-DCB MODEL DEVELOPMENT. Firstly, a regional ionospheric model is developed in order to account for the effect of ionospheric delay in the pseudorange difference equations. The basic GPS observation equations can be expressed as follows (Kleusberg and Teunissen, 1998):

$$
\begin{gathered}
P_{i}=\rho_{r}^{s}+c\left(d t_{r}-d t^{s}\right)+I_{r, i}^{s}+T_{r}^{s}+c\left(d_{r, i}+d_{i}^{s}\right)+\varepsilon_{p, i} \\
\varphi_{i}=\rho_{r}^{s}+c\left(d t_{r}-d t^{s}\right)-I_{r, i}^{s}+T_{r}^{s}+c\left(\delta_{r, i}+\delta_{i}^{s}\right)+\lambda_{i} N_{i}+\varepsilon_{\varphi, i}
\end{gathered}
$$

where $P_{i}$ and $\varphi_{i}$ are the pseudorange and carrier phase measurements in metres, respectively; $\rho_{r}^{s}$ is the satellite-receiver true geometric range; $c$ is the speed of light in vacuum; $d t_{r}$ and $d t^{s}$ are the receiver and satellite clock errors, respectively; $I_{r, i}^{s}$ the ionospheric delay; $T_{r}^{s}$ the tropospheric delay; $d_{r, i}$ and $d_{i}^{s}$ are the code hardware delays for the receiver and the satellite, respectively; $\delta_{r, i}$ and $\delta_{i}^{s}$ are the carrier phase hardware delay for the receiver and the satellite, respectively; $\lambda_{i}$ is the wavelength of carrier phase; $N_{i}$ is the non-integer phase ambiguity, and $\varepsilon_{p, i}$ and $\varepsilon_{\varphi, i}$ are the code and phase un-modelled errors, including noise and multipath.

Geometry-free linear combinations are formed using the un-differenced carriersmoothed code observations, which eliminate the geometrical term, tropospheric delay, receiver and satellite clock errors as follows (Dach et al., 2007):

$$
P_{4}=P_{2}^{-}-P_{1}^{-}=\left(\frac{f_{1}^{2}}{f_{2}^{2}}-1\right) I_{r}^{s}-c\left(D C B_{r}+D C B^{s}\right)
$$

where $P_{i}^{-}$are the smoothed code observables; $I_{r}^{s}$ is the L1 ionospheric delay; $D C B_{r}$ and $D C B^{s}$ are the differential code bias for the receiver and the satellite, respectively.

Based on Equation (3), the Slant TEC (STEC) along the satellite-receiver path can be determined as follows:

$$
S T E C=\left(\frac{f_{1}^{2} f_{2}^{2}}{40 \cdot 3\left(f_{1}^{2}-f_{2}^{2}\right)}\right)\left[P_{4}+c\left(D C B_{r}+D C B^{s}\right)\right]
$$

The Vertical TEC (VTEC) can be estimated using the Modified Single Layer Model (MSLM) mapping function, which assumes that all free electrons are concentrated in a shell of infinitesimal thickness at height $\mathrm{H}$. The effective height $(H)$ corresponds to maximum electron density at the $\mathrm{F} 2$ peak ranges from $350 \mathrm{~km}$ to $450 \mathrm{~km}$. The VTEC is determined at the Ionosphere Pierce Point (IPP), the point of intersection between the shell layer and satellite-receiver path, as given below (Schaer, 1999):

$$
V T E C=S T E C * \cos \left(\arcsin \left(\frac{R}{R+H} \sin (\alpha z)\right)\right)
$$

where $z$ is the satellite's zenith distance at the receiver; $R$ is the mean radius of the Earth, and $\alpha$ is a correction factor. Best fit of the MSLM with respect to the JPL Extended Slab Model (ESM) mapping function is achieved at $H=506.7 \mathrm{~km}$ and $\alpha=0.9782$, when using $\mathrm{R}=6371 \mathrm{~km}$ and assuming a maximum zenith distance of $80^{\circ}$ (Dach et al., 2007).

The VTEC can be modelled on a regional scale as a function $\mathrm{E}(\beta, \mathrm{s})$ of the geographic latitude ( $\beta$ ) and the sun-fixed (s) longitude of the IPP, respectively. The regional 
VTEC is expressed as a spherical harmonic expansion, which takes the form (Schaer, 1999):

$$
\mathrm{E}(\beta, \mathrm{s})=\sum_{\mathrm{n}=0}^{\mathrm{n}_{\max }} \sum_{\mathrm{m}=0}^{\mathrm{n}} \mathrm{P}_{\mathrm{nm}}^{-}(\sin \beta)\left(\mathrm{a}_{\mathrm{nm}} \cos \mathrm{ms}+\mathrm{b}_{\mathrm{nm}} \sin \mathrm{ms}\right)
$$

where $n_{\max }$ is the maximum degree of the spherical harmonic expansion; $P_{n m}^{-}$are normalised associated Legendre functions of degree $n$ and order $m ; a_{n m}$ and $b_{n m}$ are the unknown coefficients of spherical harmonics.

Substituting Equations (4) and (5) into Equation (6), the ionospheric spherical harmonic model can be expressed as:

$$
\begin{aligned}
& \sum_{n=0}^{n_{\max }} \sum_{m=0}^{n} P_{n m}^{-}(\sin \beta)\left(a_{n m} \cos m s+b_{n m} \sin m s\right) \\
& =\left(\frac{f_{1}^{2} f_{2}^{2}}{40 \cdot 3\left(f_{1}^{2}-f_{2}^{2}\right)}\right)\left[P_{4}+c\left(D C B_{r}+D C B^{s}\right)\right] * \cos \left(\arcsin \left(\frac{R}{R+H} \sin (\alpha z)\right)\right)
\end{aligned}
$$

where $a_{n m}, b_{n m}, D C B_{r}$ and $D C B^{s}$ are the unknown parameters to be computed.

In order to separate the DCBs of the receivers and satellites, an additional constraint must be used. This assumes that the sum of satellite DCBs is zero as follows (Dach et al., 2007):

$$
\sum_{s=1}^{s=\max } D C B^{s}=0
$$

After the development of the RIM, the multi-constellation GNSS receiver DCB can be estimated through the use of Equations (4) and (5) as follows:

$$
\begin{gathered}
D C B_{r}=\left(\frac{40 \cdot 3\left(f_{1}^{2}-f_{2}^{2}\right)}{c f_{1}^{2} f_{2}^{2}}\right) V T E C * M F-\left(\frac{P_{2}-P_{1}}{c}\right)-D C B^{s} \\
M F=\left[\cos \left(\arcsin \left(\frac{R}{R+H} \sin (z)\right)\right)\right]^{-1}
\end{gathered}
$$

where $M F$ is the mapping function; $P_{1}$ and $P_{2}$ are the code observations on $L_{1}$ and $L_{2}$, respectively; $f_{1}$ and $f_{2}$ are the carrier phase frequencies on $L_{1}$ and $L_{2}$, respectively; the VTEC values are extracted from the RIM file for every 15 minutes. In addition, the satellite DCBs are obtained from the available MGEX file. The receiver DCBs is computed every 15 minutes, thus the daily average value can be obtained as follows:

$$
D C B_{r, a v g}=\frac{1}{n} \sum_{i=1}^{i=n} D C B_{r}
$$

The developed MGR-DCB model uses the unsmoothed code observations, where there is no effect of the noise level on the estimated daily mean differential code bias values (Montenbruck et al., 2014).

In order to validate the developed MGR-DCB model, the combined VTEC is computed from the GPS, BeiDou and Galileo measurements by mapping the STEC from 


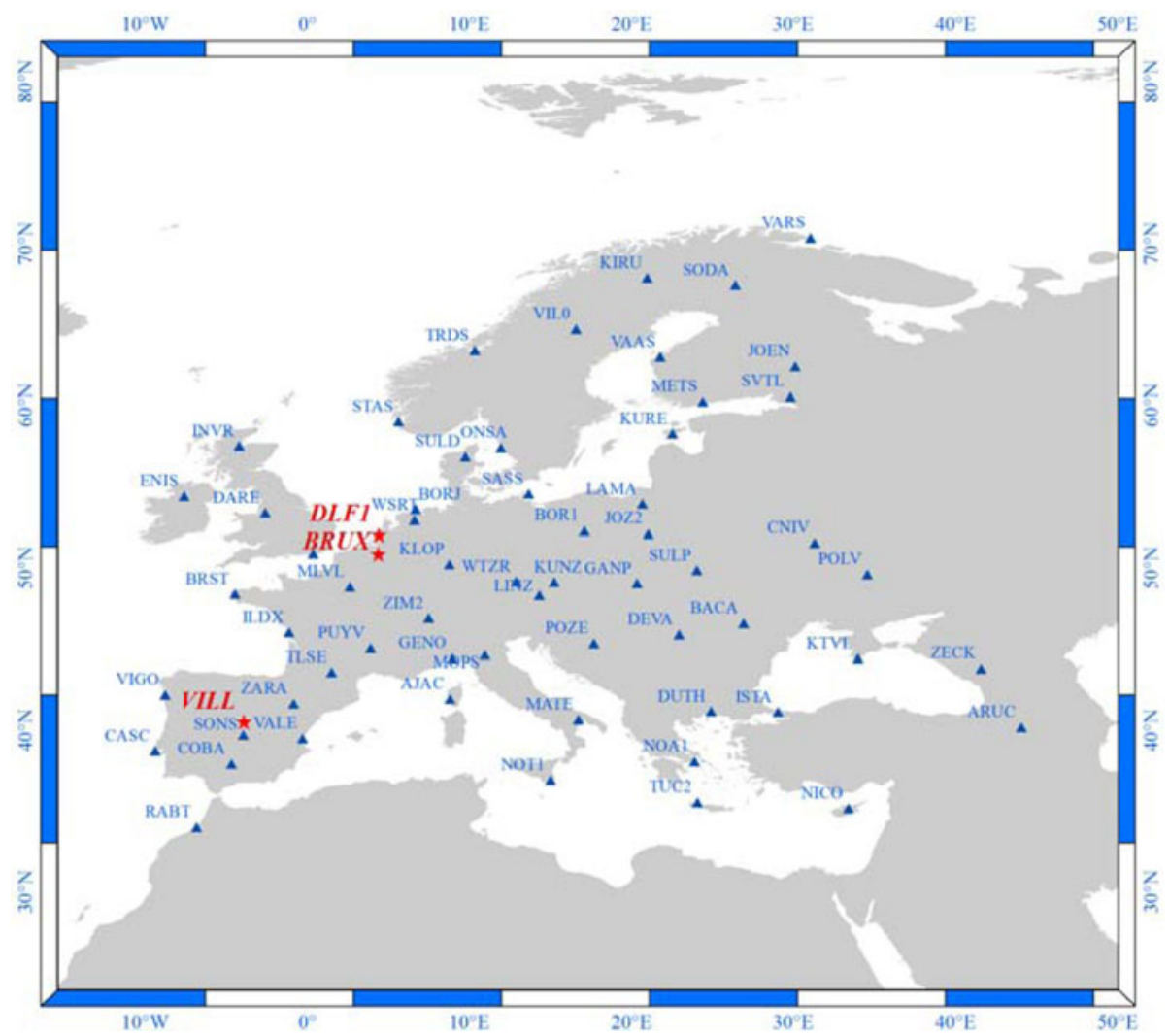

Figure 1. Reference stations distribution (with triangle shape) and examined stations (with asterisk shape).

the high elevation satellites and assuming a single VTEC for each epoch. The combined VTEC can be obtained as follows (Tang et al., 2014):

$$
\begin{gathered}
B=A X \\
{\left[\begin{array}{c}
P_{4}+c D C B_{r}+c D C B^{s=1} \\
\vdots \\
P_{4}+c D C B_{r}+c D C B^{s=n}
\end{array}\right]=\left[\begin{array}{c}
k * M F^{s=1} \\
\vdots \\
k * M F^{s=n}
\end{array}\right][V T E C]}
\end{gathered}
$$

where $n$ is the number of the observed GPS, BeiDou or Galileo satellites with high elevation angle into the single epoch; $k$ is a frequency-dependent factor, $k=$ $\frac{40 \cdot 3\left(f_{1}^{2}-f_{2}^{2}\right)}{\left(f_{1}^{2} f_{2}^{2}\right)}$. It should be pointed out that the factor $k$ has three different values for each of the GPS, BeiDou and Galileo systems.

The combined VTEC is estimated from high elevation satellites under the assumption that the computed VTEC from those satellites are approximately equal to the VTEC values at the zenith above the receiver. 


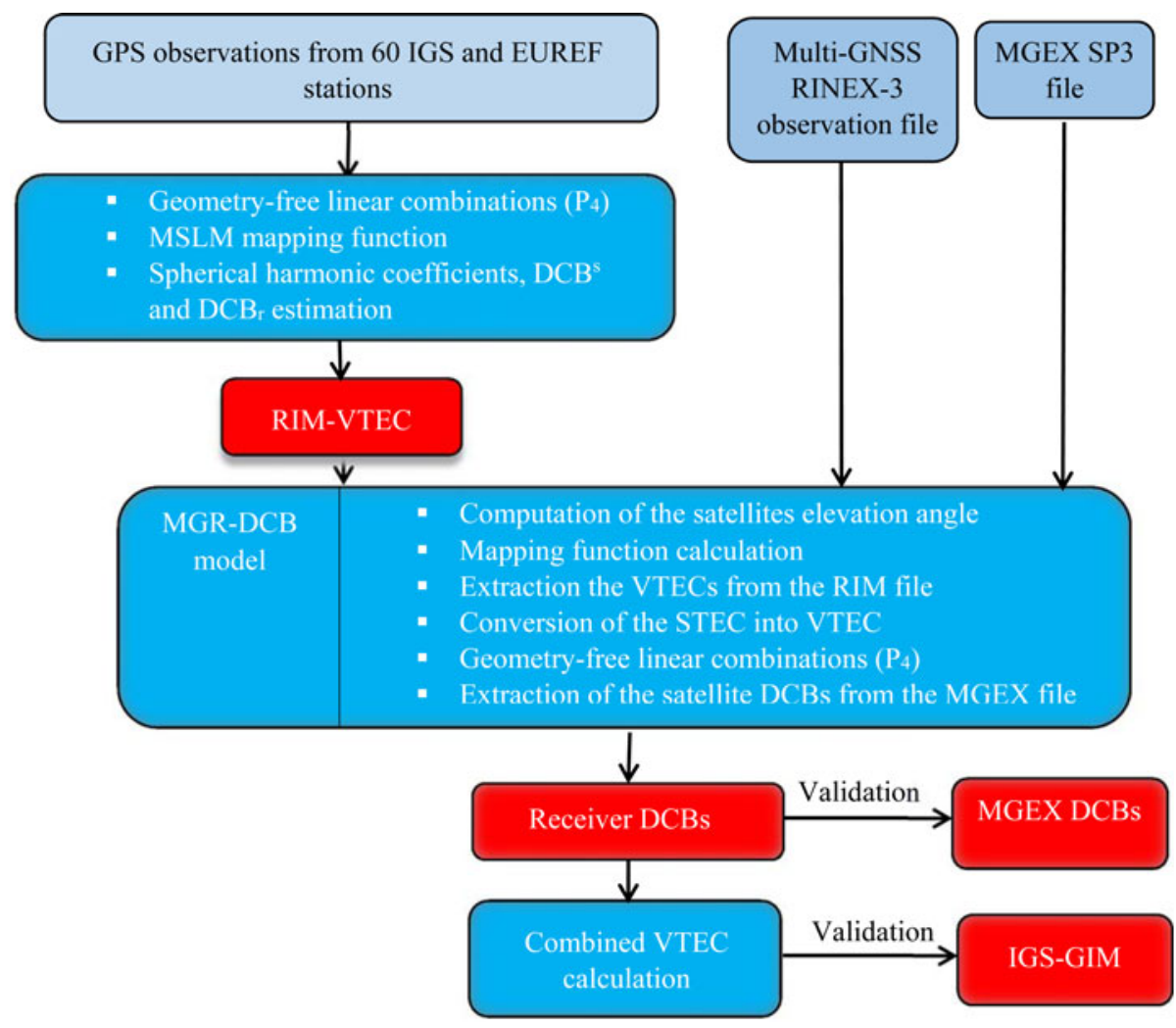

Figure 2. Flow chart of the developed MGR-DCB.

3. METHODOLOGY. A regional network consisting of 60 IGS and EUREF reference stations in Europe has been used to develop the regional ionospheric model (Figure 1). The stations are homogeneously distributed in different latitudes in order to reflect different ionospheric characteristics. GPS observations for three different days (Day of Year (DOY) 130, 200 and 362 in year 2014) have been downloaded (BKG, 2015) to represent the ionosphere seasonal variations in May, August and December, respectively. Each observation file has a 24-hour time span and a 30 -second time interval. An elevation cut-off angle of $20^{\circ}$ has been used. The files have been processed using the PPP module in the Bernese-5.20 software package. In order to produce the RIM, the IGS final satellite orbit, satellite clock and earth orientation parameters have been used (IGS, 2015) and then have been converted into the Bernese formats. The un-differenced code observations have been smoothed. In the parameters estimation process, the effective height has been selected to be $450 \mathrm{~km}$. In addition, a maximum degree and order equal to six of the spherical harmonic expansions have been selected with a 15-minute interval. A group of 49 coefficients of the spherical harmonic model has been obtained each time epoch. Thereafter, to extract the VTEC maps a spatial and temporal resolution of $1^{\circ} \times 1^{\circ}$ and 15 minutes, respectively, have been selected.

In order to estimate the receiver differential code bias, The MGR-DCB model has been developed. A FORTRAN code has been written as per the flowchart shown in 
Table 1. Examined stations characteristics.

\begin{tabular}{lrrll}
\hline Station & Latitude & Longitude & Receiver type & Antenna type \\
\hline VILL & $40 \cdot 4436$ & $356 \cdot 0480$ & SEPT POLARX4 & SEPCHOKE_MC NONE \\
BRUX & $50 \cdot 7980$ & $4 \cdot 3585$ & SEPT POLARX4TR & JAVRINGANT_DM NONE \\
DLF1 & 51.9860 & 4.3875 & TRIMBLE NETR9 & LEIAR25.R3 LEIT \\
\hline
\end{tabular}

Table 2. Estimated DCB values.

\begin{tabular}{|c|c|c|c|c|c|c|c|}
\hline \multirow[t]{2}{*}{$\mathrm{DCB}$} & \multirow[t]{2}{*}{ Station } & \multicolumn{2}{|c|}{ DOY 130} & \multicolumn{2}{|c|}{ DOY 200} & \multicolumn{2}{|c|}{ DOY 362} \\
\hline & & $\begin{array}{l}\text { MGEX } \\
(\mathrm{ns})\end{array}$ & $\begin{array}{l}\text { Estimated } \\
(\mathrm{ns})\end{array}$ & $\begin{array}{l}\text { MGEX } \\
(\mathrm{ns})\end{array}$ & $\begin{array}{l}\text { Estimated } \\
\text { (ns) }\end{array}$ & $\begin{array}{l}\text { MGEX } \\
(\mathrm{ns})\end{array}$ & $\begin{array}{l}\text { Estimated } \\
\text { (ns) }\end{array}$ \\
\hline \multicolumn{8}{|l|}{ GPS } \\
\hline \multirow[t]{2}{*}{$\mathrm{C} 1 \mathrm{~W}-\mathrm{C} 2 \mathrm{~W}$} & BRUX & $8 \cdot 80$ & $8 \cdot 63$ & $8 \cdot 15$ & 7.98 & 8.09 & $8 \cdot 10$ \\
\hline & VILL & $6 \cdot 22$ & $6 \cdot 55$ & $5 \cdot 22$ & $5 \cdot 36$ & 4.98 & $5 \cdot 45$ \\
\hline $\mathrm{C} 1 \mathrm{C}-\mathrm{C} 2 \mathrm{~W}$ & DLF1 & $-17 \cdot 38$ & $-17 \cdot 70$ & $-17 \cdot 79$ & -17.99 & -17.97 & $-18 \cdot 09$ \\
\hline \multirow[t]{2}{*}{ C1C-C5Q } & BRUX & $-1 \cdot 38$ & $-2 \cdot 04$ & $-2 \cdot 82$ & $-3 \cdot 06$ & $-0 \cdot 88$ & $-1 \cdot 00$ \\
\hline & VILL & $-2 \cdot 62$ & $-2 \cdot 53$ & $-4 \cdot 17$ & $-4 \cdot 11$ & $-4 \cdot 08$ & $-3 \cdot 88$ \\
\hline C1C-C5X & DLF1 & $-17 \cdot 60$ & $-18 \cdot 42$ & $-18 \cdot 83$ & -18.93 & $-19 \cdot 16$ & $-19 \cdot 28$ \\
\hline \multicolumn{8}{|l|}{ BeiDou } \\
\hline \multirow[t]{2}{*}{ C2I-C7I } & BRUX & $19 \cdot 35$ & $19 \cdot 66$ & $19 \cdot 28$ & $18 \cdot 54$ & $20 \cdot 55$ & $20 \cdot 41$ \\
\hline & VILL & $16 \cdot 52$ & 15.94 & $15 \cdot 75$ & 14.98 & $16 \cdot 70$ & $17 \cdot 53$ \\
\hline C2I-C6I & DLF1 & $45 \cdot 35$ & $45 \cdot 04$ & $44 \cdot 74$ & $43 \cdot 88$ & $46 \cdot 19$ & $45 \cdot 59$ \\
\hline C2I-C7I & DLF1 & $21 \cdot 53$ & $21 \cdot 20$ & $21 \cdot 14$ & $20 \cdot 35$ & $23 \cdot 04$ & $22 \cdot 52$ \\
\hline \multicolumn{8}{|l|}{ Galileo } \\
\hline \multirow[t]{2}{*}{ C1C-C5Q } & BRUX & $1 \cdot 06$ & $0 \cdot 13$ & $1 \cdot 26$ & $1 \cdot 40$ & $2 \cdot 88$ & $2 \cdot 91$ \\
\hline & VILL & $0 \cdot 14$ & -0.03 & -0.59 & $0 \cdot 24$ & $-0 \cdot 43$ & $0 \cdot 29$ \\
\hline \multirow[t]{2}{*}{ C1C-C7Q } & BRUX & $12 \cdot 62$ & $11 \cdot 72$ & $12 \cdot 70$ & $12 \cdot 74$ & $13 \cdot 04$ & $13 \cdot 07$ \\
\hline & VILL & $10 \cdot 54$ & $10 \cdot 33$ & $9 \cdot 93$ & $10 \cdot 67$ & $10 \cdot 08$ & $10 \cdot 67$ \\
\hline \multirow[t]{2}{*}{ C1C-C8Q } & BRUX & $8 \cdot 74$ & $7 \cdot 93$ & $9 \cdot 01$ & $9 \cdot 14$ & $9 \cdot 78$ & $9 \cdot 72$ \\
\hline & VILL & $7 \cdot 39$ & $7 \cdot 30$ & $6 \cdot 88$ & $7 \cdot 58$ & 6.99 & $7 \cdot 65$ \\
\hline C1X-C5X & DLF1 & $-0 \cdot 47$ & $-0 \cdot 81$ & $0 \cdot 27$ & 0.09 & $-0 \cdot 46$ & $-0 \cdot 66$ \\
\hline C1X-C7X & DLF1 & $1 \cdot 77$ & $2 \cdot 04$ & $2 \cdot 46$ & $2 \cdot 35$ & $2 \cdot 41$ & $2 \cdot 78$ \\
\hline C1X-C8X & DLF1 & $-0 \cdot 16$ & $-1 \cdot 13$ & 0.73 & $0 \cdot 15$ & 0.35 & $0 \cdot 51$ \\
\hline
\end{tabular}

Figure 2. The VTEC values have been extracted from the RIM file at a 15-minute time interval. The estimation of the satellite DCB needs a well-distributed network, however, only three stations have been examined, therefore the satellite DCBs available from MGEX website (MGEX, 2015) has been used.

4. RESULTS AND ANALYSIS. In order to assess the developed MGR-DCB model, the receiver DCBs for another set of reference stations was computed (Figure 1). The DCBs for the EUREF stations were not available, therefore only the MGEX stations were examined. The examined stations were selected to represent different latitudes and receiver types (Table 1). The legacy GPS DCBs for the P(Y)-code on the $\mathrm{L} 1$ and $\mathrm{L} 2$ tracking signals $(\mathrm{C} 1 \mathrm{~W}-\mathrm{C} 2 \mathrm{~W})$ was assessed. In addition, the DCBs for the GPS L1 C/A tracking and the L2 P(Y) tracking $(\mathrm{C} 1 \mathrm{C}-\mathrm{C} 2 \mathrm{~W})$ was computed. Thereafter, the DCBs for the modernised GPS civil L5 signal with the different tracking mode used by the MGEX receivers (i.e., C1C-C5Q and C1C-C5X) were 

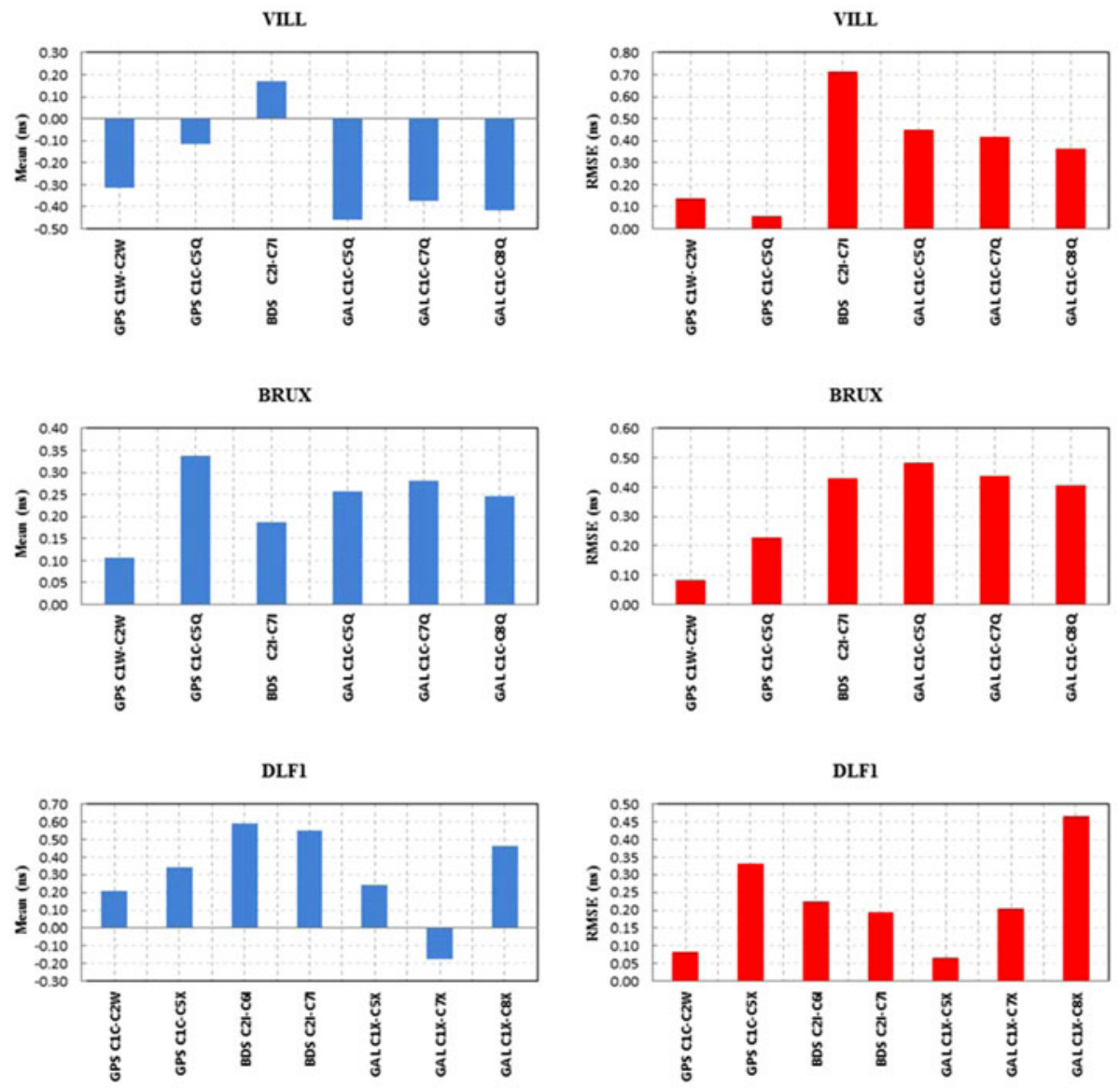

Figure 3. DCBs mean and RMSE values.

determined. For the BeiDou system, the DCBs for the three signals B1, B2 and B3 (C2I-C6I and C2I-C7I) were evaluated. For the Galileo E1, E5a, E5b and E5 signals, the $\mathrm{DCBs}$ for the receiver pilot-tracking mode, indicated by $\mathrm{C} 1 \mathrm{C}-\mathrm{C} 5 \mathrm{Q}$, $\mathrm{C} 1 \mathrm{C}-\mathrm{C} 7 \mathrm{Q}$ and $\mathrm{C} 1 \mathrm{C}-\mathrm{C} 8 \mathrm{Q}$ were determined. In addition, the $\mathrm{C} 1 \mathrm{X}-\mathrm{C} 5 \mathrm{X}, \mathrm{C} 1 \mathrm{X}-\mathrm{C} 7 \mathrm{X}$ and C1X-C8X DCBs for the receiver combined (pilot and data) tracking mode were estimated.

Table 2 outlines the estimated multi-GNSS receiver DCBs for the examined stations in the three days and for the different receiver tracking modes. It is shown that the estimated DCBs from the MGR-DCB model have good agreement with the IGS-MGEX values.

Figure 3 shows the mean difference and the RMSE of the receiver DCBs obtained from the MGR-DCB with respect to the IGS-MGEX DCBs values. For the legacy GPS C1W-C2W DCBs, it is shown that the mean difference is about $-0 \cdot 31 \mathrm{~ns}$ and $0 \cdot 11 \mathrm{~ns}$ for station VILL and BRUX, respectively. For their RMSE values, they are about $\pm 0.14 \mathrm{~ns}$ and $0.08 \mathrm{~ns}$, respectively. The mean difference of the $\mathrm{C} 1 \mathrm{C}-\mathrm{C} 2 \mathrm{~W}$ DCB for station DLF1 is about $0.21 \mathrm{~ns}$ with $\pm 0.08 \mathrm{~ns}$ RMSE value. For the 

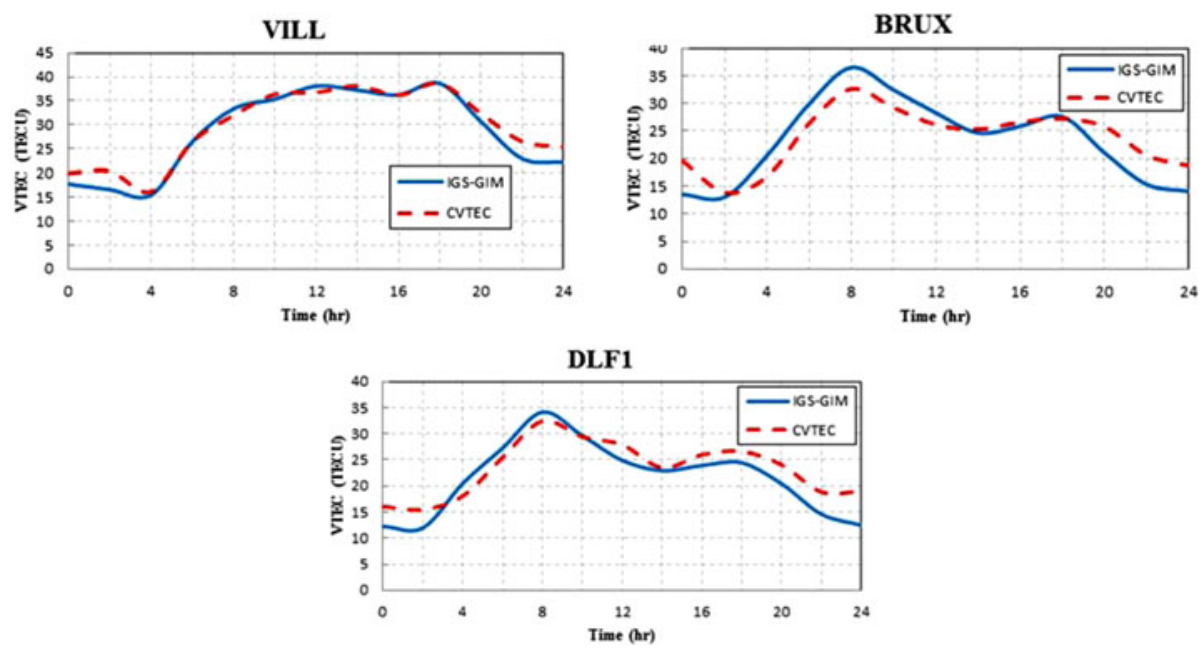

Figure 4. VTEC profiles on DOY 130.

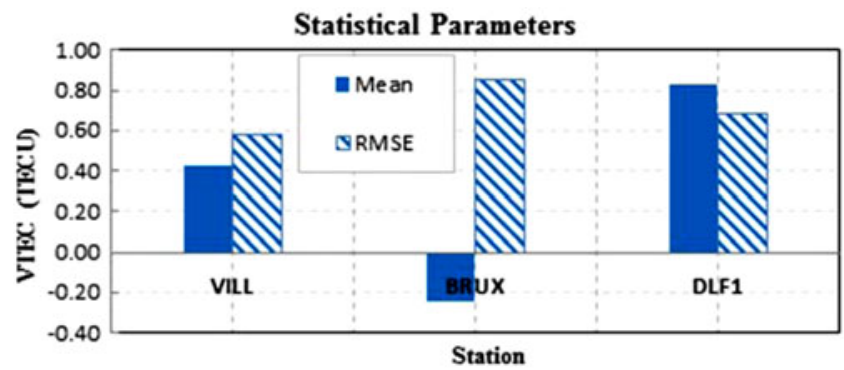

Figure 5. Statistical parameters for the CVTEC differences.

modernised GPS L5 signal, the discrepancy between the estimated and MGEX is about $-0 \cdot 12 \mathrm{~ns}, 0.34 \mathrm{~ns}$ and $0.34 \mathrm{~ns}$ for station VILL, BRUX and DLF1, respectively. In addition, the RMSE values are about $\pm 0 \cdot 06,0.23$ and 0.33 ns for station VILL, BRUX and DLF1, respectively.

The BeiDou (C2I-C7I) differential code bias estimated from the MGR-DCB model show offsets from the MGEX values about $0 \cdot 17,0 \cdot 19$ and $0.55 \mathrm{~ns}$ with RMSE values about $\pm 0 \cdot 71,0.43$ and 0.19 ns for stations VILL, BRUX and DLF1, respectively. The BeiDou B3 signal can be tracked by station DLF1, thus its C2I-C6I DCB shows a mean difference of $0.59 \mathrm{~ns}$ with a RMSE value of $\pm 0 \cdot 22 \mathrm{~ns}$.

The resulting Galileo E1-E5a differential code biases exhibit mean differences from the MGEX values about $-0 \cdot 46,0 \cdot 26$ and $0 \cdot 24$ ns for stations VILL, BRUX and DLF1, respectively. In addition, the RMSE of the VILL, BRUX and DLF1 are $\pm 0 \cdot 45,0 \cdot 48$ and $0.07 \mathrm{~ns}$, respectively. For the resulting E1-E5b DCBs, the mean discrepancies are $-0 \cdot 37,0 \cdot 28$ and $-0 \cdot 17 \mathrm{~ns}$, while the RMSE values are $\pm 0 \cdot 42,0 \cdot 44$ and $0 \cdot 20 \mathrm{~ns}$ for 
stations VILL, BRUX and DLF1, respectively. The mean differences for the estimated E1-E5 DCBs are $-0 \cdot 42,0 \cdot 25$ and 0.46 ns with RMSE values $\pm 0 \cdot 36,0 \cdot 41$ and 0.47 ns for stations VILL, BRUX and DLF1, respectively.

It is shown from the above results that the mean difference between the estimated receiver DCBs and MGEX counterparts is less than $1 \mathrm{~ns}$. In addition, the RMSE for the three examined stations is also less than $1 \mathrm{~ns}$. This level of agreement means that the ionospheric correction values obtained through the developed regional ionospheric model are accurate. However, the station location contributes to the accuracy of the computed ionospheric value. This appears for station DLF1, where the mean difference is large (Figure 3). This is due to the fact that station DLF1 is located at the border of the developed ionospheric model as shown in Figure 1.

In order to validate the model, the Combined Vertical Total Electron Content (CVTEC) are computed from the GPS, Galileo and BeiDou measurements and then compared with the IGS-GIM counterparts. For illustration purposes, only the VTEC profiles for stations VILL, BRUX and DLF1, respectively on DOY 130 are given in Figure 4.

Figure 5 illustrates the mean differences and RMSE values of the CVTEC with respect to the IGS-GIM counterparts for the three examined stations. It is shown that for station VILL the mean difference is about 0.4226 TECU with RMSE value about \pm 0.5833 TECU. For station BRUX, the mean discrepancy is -0.2454 TECU, while the RMSE is \pm 0.8528 TECU. In addition, the mean difference and RMSE values for station DLF1 are 0.8259 TECU and $\pm 0 \cdot 6881$ TECU, respectively.

5. CONCLUSION. In this paper, a Multi-frequency multi-GNSS Receiver Differential Code Bias estimation model has been developed using the ionosphere-corrected geometry-free linear combinations of the pseudorange observations. In order to correct the pseudorange differences from the ionospheric delay, a Regional Ionospheric Model over Europe has been developed using GPS observations. The developed RIM has spatial and temporal resolutions of $1^{\circ} \times 1^{\circ}$ and 15 minutes, respectively. To validate the proposed model, the receiver DCBs for GPS, Galileo and BeiDou signals have been estimated for three MGEX stations over three different days. It has been shown that the estimated DCBs have good agreement with the MGEX values, with mean difference and RMSE values less than 1 ns. In addition, the combined GPS, BeiDou and Galileo VTEC have been assessed and compared with the IGS-GIM counterparts. The findings showed good agreement with the IGS-GIM values with mean difference and RMSE values less than 1 TECU.

\section{REFERENCES}

Abdelazeem, M., Çelik, R.N. and El-Rabbany, A. (2015). An enhanced real-time regional ionospheric model using IGS real-time service (IGS-RTS) products. Journal of Navigation, http://dx.doi.org/10.1017/ S0373463315000740

Arikan, F., Nayir, H., Sezen, U. and Arikan, O. (2008). Estimation of single station interfrequency receiver bias using GPS-TEC. Radio Science, 43, RS4004 (13 pp.).

BKG. (2015). Agency for Cartography and Geodesy. ftp://igs.bkg.bund.de/. Accessed 1 April 2015.

Choi, B. K., Cho, J. H. and Lee, S. J. (2011). Estimation and analysis of GPS receiver differential code biases using KGN in Korean Peninsula. Advances in Space Research, 47, 1590-1599. 
Dach, R., Hugentobler, U., Fridez, P. and Meindl, M. (2007). Bernese GPS Software Version 5.0. Astronomical Institute, University of Berne (AIUB).

IGS. (2015). International GNSS Service,. ftp://cddis.gsfc.nasa.gov/. Accessed 1 April 2015.

Jin, R., Jin, S. and Feng, G. (2012). M_DCB: Matlab code for estimating GNSS satellite and receiver differential code biases. GPS Solutions, 16, 541-548.

Julien, O., Issler, J.-L. and Lestarquit, L. (2012). Ionospheric delay estimation using Galileo E5 signals only. 25th International Technical Meeting of the Satellite Division of the Institute of Navigation, ION GNSS 2012, Nashville, TN, United states. pp 286-301.

Kao, S., Tu, Y., Chen, W., Weng, D. J. and Ji, S. Y. (2013). Factors affecting the estimation of GPS receiver instrumental biases. Survey Review, 45, 59-67.

Keshin, M. (2012). A new algorithm for single receiver DCB estimation using IGS TEC maps. GPS Solutions, 16, 283-292.

Kleusberg, A. And Teunissen, P.J.G. (1998). GPS for geodesy, Springer, Berlin, Federal Republic of Germany.

Li, Z., Yuan, Y., Li, H., Ou, J. and Huo., X. (2012). Two-step method for the determination of the differential code biases of COMPASS satellites. Journal of Geodesy, 86, 1059-1076.

MGEX (2015). IGS Multi-GNSS Experiment. ftp://cddis.gsfc.nasa.gov/gps/products/mgex. Accessed 1 April 2015.

Montenbruck, O., Hauschild, A. and Steigenberger, P. (2014). Differential code bias estimation using multiGNSS observations and global ionosphere maps. Institute of Navigation International Technical Meeting 2014, San Diego, CA, United States. Institute of Navigation, 802-812.

Sardon, E. and Zarraoa, N. (1997). Estimation of Total Electron-Content Using GPS Data: How Stable Are the Differential Satellite and Receiver Instrumental Biases. Radio Science, 32, 1899-1910.

Schaer, S. (1999). Mapping and Predicting the Earth's Ionosphere Using the Global Positioning System. PhD Thesis, University of Bern, Switzerland.

Tang, W., Jin, L. and Xu, K. (2014). Performance analysis of ionosphere monitoring with BeiDou CORS observational data. Journal of Navigation, 67, 511-522.

Tu, R, Ge, M., Zhang, H. and Huang, G. (2013). The realization and convergence analysis of combined PPP based on raw observation. Advances in Space Research, 52, 211-221.

Wei, C., Zhang, Q., Fan, L., Zhang, S., Huang, G. and Chen, K. (2014). Estimate DCB of BDS satellites based on the observations of GPS/BDS. 5th China Satellite Navigation Conference, CSNC 2014, Nanjing, China. Springer Verlag, 351-362.

Zhang, Q., Zhao, Q., Zhang, H. and Chen, G. (2014). BDS satellites and receivers DCB resolution. 5th China Satellite Navigation Conference, CSNC 2014, Nanjing, China. Springer Verlag, 187-197.

Zhang, R., Song, W.-W., Yao, Y.-B., Shi, C., Lou, Y.-D. and Yi, W.-T. (2015). Modelling regional ionospheric delay with ground-based BeiDou and GPS observations in China. GPS Solutions, 19, 649-658. 